\title{
Making pavilions: Os pavilhões temporários no contexto das faculdades de arquitetura e urbanismo
}

\author{
Making pavilions: The temporary pavilions in the context of schools of architecture and \\ urbanism \\ Ivvy Pedrosa Cavalcante Pessôa Quintella \\ Universidade Federal de Alagoas, Brasil \\ ivvyp@yahoo.com \\ Ítalo Cintra Ferreira \\ Universidade Federal de Alagoas, Brasil \\ italocintra@gmail.com
}

Eduardo Quintella Florêncio

Universidade Federal de Alagoas, Brasil

eduardogf@hotmail.com

\begin{abstract}
This paper aims to highlight the educational potential of the association between the architectural typology of temporary pavilions and digital fabrication process for architecture and urban planning courses. The pavilion theme is being increasingly exploited in various universities in the world, in order to work new paradigms of computational algorithmic architecture and new construction process, through digital fabrication labs. In this sense, these exercises can become a privileged and highly effective learning tool, due the impact of the integrated experience between creating (design), construction (to build) and experience (to appropriate the spaces).
\end{abstract}

Keywords: Temporary pavilions; Digital manufacturing; Rapid prototyping; Construction; Architecture education.

\section{Introdução}

Esta comunicação objetiva destacar as potencialidades didáticas e de pesquisa da associação entre a tipologia arquitetônica dos pavilhões temporários e a experimentação possibilitada pelos processos de fabricação digital para os cursos de arquitetura e urbanismo. Apresentam-se resultados parciais de um dos eixos da pesquisa intitulada "O campo ampliado da arquitetura", que enfoca o impacto da produção de pavilhões de estudo integrada à formação acadêmica do arquiteto e urbanista.

A partir do mapeamento de exemplares efetuado na pesquisa, constatou-se uma crescente concretização de experiências de pavilhões de estudo em escala real nos últimos dez anos, ampliando-se de modo exponencial nos últimos dois anos. Esse dado deve ser associado à popularização do acesso aos processos de fabricação digital por meio de laboratórios do tipo fab lab, cada vez mais presentes no contexto das universidades. A tipologia do pavilhão passou a ser recorrentemente utilizada como tema de exercícios didáticos nas disciplinas projetuais, bem como em workshops que envolvem associações entre concepção da forma, programas de desenho paramétrico, algoritmos generativos e processos de fabricação digital.

As possibilidades didáticas da temática aqui exposta não se circunscrevem ao "estudo da forma arquitetônica". A tipologia do pavilhão temporário pode estimular e fornecer subsídios à elaboração de exercícios práticos de integração vertical e horizontal entre diversas disciplinas, para além das de "concepção da forma", tais como: expressão gráfica, detalhamento, teoria do projeto, informática, paisagismo, materiais e sistemas estruturais, teoria e história da arquitetura. Seu potencial está na possibilidade de explorar, na integração entre tais disciplinas, o entrecruzamento entre teoria e prática, dado que elas ainda são concebidas como habilidades "isoladas" em muitas escolas de arquitetura.

O conhecimento das possibilidades proporcionadas pelos processos tecnológicos digitais, especialmente os de fabricação, pode ter um considerável impacto nas decisões de projeto. Todavia, acredita-se que seu impacto pode ir mais além: A realização de pavilhões no contexto acadêmico pode ser compreendida como parte de um novo processo de concepção em arquitetura, que visa estabelecer uma conexão mais direta entre o projetar, o produzir e o experimentar. Esses processos integradores contemporâneos têm potencial para revolucionar a forma como se aprende arquitetura e sua atual estrutura acadêmica de ensino.

Outro fator de extrema importância é a conectividade e a troca de experiências entre laboratórios de fabricação digital, em especial os da Rede Fab Lab originada no MIT. Ao partilhar projetos e processos, tais laboratórios vêm integrando os princípios do open design e do projeto colaborativo na academia, estimulando o pensamento transdisciplinar entre múltiplos campos do conhecimento, ao espírito "crowdthinking". 
A partir de uma breve contextualização sobre a tipologia do pavilhão temporário e sua importância para a arquitetura contemporânea, o estudo apresenta exemplos construídos desenvolvidos em faculdades de arquitetura e urbanismo, discutindo seu potencial didático e de pesquisa.

\section{Pavilhões temporários}

Os pavilhões temporários podem ser definidos como construções efêmeras destinadas a eventos, exposições ou experimentações construtivas. Dado seu caráter experimental e interativo, trata-se de um tema privilegiado para investigar novos paradigmas de apropriação dos espaços públicos e de concepção da forma em arquitetura, enfocando as múltiplas possibilidades abertas pela fabricação digital. Apesar de sua utilização recorrente como construção experimental na arquitetura contemporânea, a tipologia do pavilhão temporário é um tema ainda pouco explorado em pesquisas no Brasil.

Os pavilhões temporários podem funcionar como uma espécie de "ativador" de um espaço, transformando-o, ainda que efemeramente, em "lugar". Eles proporcionam uma quebra de leitura no contexto cotidiano, gerando atratividade e transformando a compreensão e apropriação dos espaços públicos em que se inserem. A liberdade proporcionada pela pouca restrição do programa funcional se presta à concretização de experimentações projetuais e construtivas, pois permite explorar formas livres e complexas. De acordo com 0 arquiteto Ben Van Berkel, pode-se fazer uma analogia com a música, pois o pavilhão propõe uma experiência apreciativa tanto mais intensa quanto for evidenciada a sua inerente temporalidade.

Assim, seu caráter de catalizador de situações associa-se tanto à ideia de "evento" quanto ao estranhamento provocado por novas formas de interação com a paisagem urbana. Esses experimentos construtivos também se associam com a escala humana, com a experiência exploratória do corpo e da sensorialidade, com a descoberta em camadas de significados, e sua relação com o contexto espacial. Tais questões aproximam a arquitetura de certas pesquisas da arte contemporânea, como a instalação, o site specific e as intervenções urbanas. Nesse sentido, trata-se de conceitos que promovem abordagens interdisciplinares e confluem com a ideia de arquitetura em campo ampliado (VIDLER, in: SYKES, 2013).

Malgrado sua associação com as pesquisas da arte e da arquitetura contemporâneas, o pavilhão possui uma longínqua história enquanto tipologia arquitetural. O termo pavilhão advém do latim papilio, borboleta, e alude ao caráter transitório das tendas dos acampamentos militares romanos. Identifica-se historicamente a existência de uma diversidade de caráteres e de funções. A ideia moderna de pavilhão temporário como construção efêmera destinada a abrigar eventos tem seu exemplo inaugural no Palácio de Cristal, de Joseph Paxton, construído em Londres para a primeira exposição universal (1851). Desde então, os pavilhões ampliaram o seu caráter simbólico, tornando-se também elementos de ostentação das glórias artísticas e tecnológicas das nações.

Tais espaços de exibição tornaram-se, também, ocasião privilegiada de exploração formal e de apresentação de novos paradigmas arquitetônicos e estruturais por arquitetos célebres, tais como o pavilhão de Barcelona, por Mies Van der Rohe, e o pavilhão Philips, por Le Corbusier e Xenakis (PUENTE, 2000), entre outros. É um tema particularmente adequado para explorar especulações em torno do futuro da arquitetura e as tendências do pensamento arquitetônico. Assim, o entendimento da tipologia de pavilhões temporários vem passando de lugares criados para abrigar exposições, para se tornarem eventos cuja "exposição" é configurada por eles mesmos, sua concepção arquitetônica e sua conexão com a paisagem urbana.

Destaca-se o célebre caso dos pavilhões anuais promovidos pela Serpentine Gallery nos Jardins de Kensington, em Londres, o mais completo programa de arquitetura/ arte desse tipo no mundo. Tais estruturas temporárias, erguidas junto à própria galeria por um período de três meses, vêm se concretizando durante o verão desde o ano 2000. Eles funcionam como um espelho do momento contemporâneo, indiciando novos caminhos da arquitetura internacional, e também como uma "vitrine" do star system. Esse programa de produção anual de pavilhões também veio a ser exemplo fundamental para 0 desenvolvimento de experiências acadêmicas nele inspirados, tais como os pavilhões de verão da Architectural Association (AA).

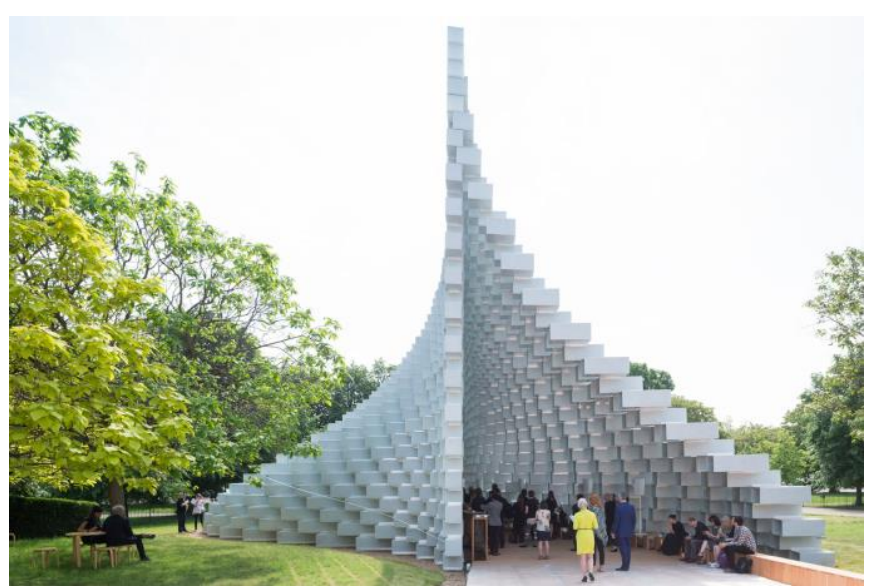

Figura 1: Pavilhão Serpentine Gallery de 2016, concebido por Bjarke Ingels Group (BIG). Fonte: www.archidaily.com

O pavilhão de 2016, concebido por Bjarke Ingels Group (BIG), foi concebido a partir de blocos geométricos simples e brancos formando uma complexa estrutura escultórica que se descortina em duas paredes onduladas. Como exemplo das possibilidades da manipulação algorítmica da estruturabase, o sítio eletrônico Archdaily disponibilizou em sua página o simulador intitulado "Brinque com a versão paramétrica do Serpentine Pavilion do BIG". Por meio da plataforma Achilogic, simula-se, diretamente no navegador web, as possibilidades de variação formal do projeto. Ao propor a participação interativa do público na manipulação da forma, evidenciou-se a concepção projetual inspirada no 
espírito do jogo de blocos de montar do tipo Lego. É uma maneira lúdica de ilustrar a concepção arquitetônica relacionada a processos generativos da forma, que permitem desenvolver uma grande família de soluções formais a partir da definição de uma estrutura inicial básica.

O pavilhão temporário pode ser considerado uma das tipologias arquitetônicas mais utilizadas para investigar novas formas, técnicas e materiais, configurando-se muitas vezes em uma espécie de "laboratório criativo" (BERGDOLL, 2010; CURTIS, 2008; JODIDIO, 2011). A natureza temporária do pavilhão cria uma oportunidade para testar novos materiais e processos construtivos, mas também para experimentar ideias teóricas e conceituais. Os pavilhões aproveitam essa liberdade de invenção para desenvolver novas possibilidades projetuais que, apesar de mais complexas, estão mais ligadas aos processos construtivos digitalmente fabricados. Pode-se considerar que, a partir das possibilidades projetuais abertas pela arquitetura algorítmica computacional e da fabricação digital, a complexidade formal e construtiva dos pavilhões temporários vêm se ampliando enormemente.

Do ponto de vista tectônico, investiga-se a utilização de materiais adequados à arquitetura efêmera, relacionando-se a rapidez de montagem, as técnicas de encaixe e as possibilidades de reutilização do material após a desmontagem. A exploração das possibilidades da fabricação digital por meio da tecnologia "connect to computer" (CNC) é um dos diferenciais dos pavilhões contemporâneos, visto que hoje é possível concretizar estruturas antes impossíveis de serem fabricadas com os meios tradicionais. Assim, é dada hoje a possibilidade de, literalmente, construir ideias complexas em arquitetura.

O estudo das experiências de concepção de pavilhões contemporâneos pode contribuir para a compreensão de processos de projetação que envolvem a experimentação de novas linguagens artísticas, arquitetônicas e urbanas, contribuindo para a noção de campo ampliado da arquitetura.

\section{Metodologia}

A pesquisa desenvolvida consistiu em identificar e catalogar experiências de concretização de pavilhões de estudo através da fabricação digital no âmbito de faculdades de arquitetura e urbanismo. Buscou-se enfocar exemplares de pavilhões que se destaquem pelo seu caráter inovador dos pontos de vista do processo projetual, privilegiando a noção de arquitetura algorítmica e a exploração de formas complexas. Selecionou-se estudos de caso para comparação e análise.

O estudo concentrou-se nos pavilhões temporários desenvolvidos a partir da exploração de técnicas e ferramentas de modelagem e fabricação digital durante o processo, investigando novas formas de pensar o ambiente construído. A pesquisa integra uma abordagem interdisciplinar com o campo da tecnologia digital, visto que enfoca propostas se valem de softwares que permitem a modelagem paramétrica e programação de algoritmos generativos da forma a partir de parâmetros definidos pelo arquiteto, tal como o plug-in Grasshopper para o software Rhinoceros, gerando estruturas complexas concretizadas por meio da fabricação digital. Enfocam-se dois tipos de experiência: 1- pavilhões desenvolvidos por grupos de pesquisa, que envolvem processos mais avançados relacionados à fabricação robótica; 2- pavilhões como resultado prático de disciplinas ou workshops abertos, que se vale de materiais mais acessíveis, como placas compensadas de madeira ou papelão.

Selecionaram-se inicialmente um conjunto de trinta pavilhões de estudo, projetados e construídos entre os anos 2000 e 2015. Tais exemplares foram catalogados em uma tabela que incluiu: imagem, ano de produção, nome do pavilhão, nome da universidade, autores, o principal material em que o pavilhão foi produzido e as técnicas utilizadas na sua concepção e elaboração. A partir do inventário e das análises desenvolvidas na pesquisa, enfocou-se alguns estudos de caso em que a experiência transcendeu a prototipagem e foi concretizada em escala 1:1. Propôs-se estudar as experiências de concretização de pavilhões através de laboratórios acadêmicos de fabricação digital, especialmente os elaborados por estudantes de forma integrada e participativa no âmbito da própria universidade.

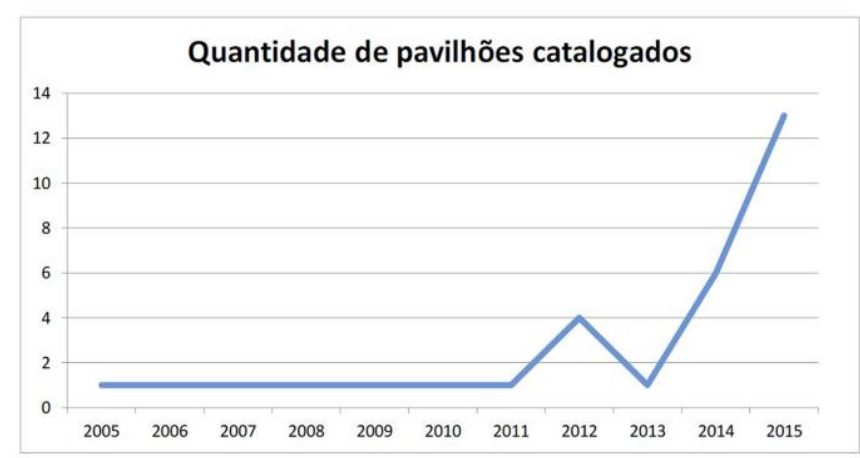

Figura 2: Número de pavilhões catalogados, distribuídos anualmente. Fonte: os autores.

A metodologia desenvolvida na pesquisa apoia-se em três principais campos instrumentais: 1- A teoria da arquitetura e do urbanismo, visando fornecer o embasamento necessário na contextualização da produção estudada, bem como acerca dos diferentes processos de projeto e metodologias de concepção da forma; 2- a análise gráfica, que é entendida como um método de fundamental importância para a compreensão das características formais dos edifícios e suas relações com a paisagem urbana; As análises gráficas compreendem a elaboração de decomposições da forma em axonometrias, mapas de figura/fundo, diagramas, detalhes estruturais, croquis de conceito, entre outros, adaptados de acordo com as particularidades do caso estudado; 3- o desenvolvimento de maquetes volumétricas por meio da prototipagem rápida com fabricação digital dos estudos de caso, visando despertar os alunos para as potencialidades da maquete física, tanto como meio de representação e análise projetual quanto como instrumento do processo de projeto. 
A pesquisa também se valeu de uma contextualização dos laboratórios de fabricação digital e fab labs, buscando relacionar sua existência nas faculdades às experiências de concretização de pavilhões de estudo. Em todos os casos levantados, a produção de pavilhões só foi possibilitada pela presença de laboratórios de fabricação no âmbito acadêmico. Evidencia-se, assim, a necessidade de uma estrutura física e de maquinários que possibilitem efetivamente a exploração das novas possibilidades de concepção e fabricação em arquitetura.

\section{Laboratórios de fabricação digital}

Um aspecto a ser talvez considerado como "revolucionário" é o impacto da integração dos meios de fabricação digital (impressoras 3D, máquinas de corte a laser, fresadoras $\mathrm{CNC}$, etc.) ao contexto da academia, iniciado timidamente há cerca de quinze anos. A partir do recente barateamento dos equipamentos e popularização dos processos, os laboratórios de fabricação digital tornaram-se espaços essenciais de experimentação projetual da forma estrutural, arquitetônica, urbana e do design, integrando os princípios de laboratório computacional e de maquetaria, anteriormente completamente separados.

Para além das simulações em ambiente computacional, o acesso aos equipamentos de fabricação digital vem gerando a possibilidade de trabalhar a experiência de prototipagem rápida e construtiva com os alunos, integrando-se a um dos princípios da cultura maker, o de "construir para pensar". Diversas universidades brasileiras vêm adquirindo tais equipamentos, estruturando fab labs associados à rede originada no MIT, ou laboratórios de fabricação digital independentes (SPERLING; HERRERA, 2015). Essa estrutura, recentíssima no Brasil, já é uma realidade cotidiana em grandes escolas de arquitetura estrangeiras.

$\mathrm{Na}$ era digital, com a facilidade de produção de imagens virtuais, a produção de maquetes parecia tender a desaparecer. A popularização da modelagem 3D e da renderização no contexto da universidade havia obscurecido o papel do modelo físico no processo de projeto. No entanto, comparada a um modelo virtual, o protótipo se coloca como um meio de transposição entre a virtualidade do projeto e a fisicalidade do objeto. Nesse sentido, a maquete física transmite mais informações ao projetista, pois permite a interação física direta e estimula percepções além da visão. A democratização do acesso à fabricação digital na academia vem revertendo esse quadro e recolocando a produção de protótipos como ferramenta essencial do processo conceptivo.

Os laboratórios de fabricação acadêmicos podem ser independentes ou fab labs. Um Fab Lab (fabrication laboratory) é um laboratório de fabricação digital afiliado a uma rede mundial originada no Instituto de Tecnologia de Massachussets (MIT/EUA). Essa rede colaborativa global possui hoje mais de 660 laboratórios associados espalhados por mais de oitenta países, nos cinco continentes. Fundado há dez anos, o Fab Lab Network vem se expandindo exponencialmente em todo o mundo. Tal crescimento se deve ao seu potencial de estímulo à inovação, ao empreendedorismo e à democratização do conhecimento.

Os docentes podem valer-se do espaço do laboratório para ministrar aulas, estimulando os alunos a desenvolver trabalhos práticos de fabricação digital nas diversas esferas (graduação, mestrado e doutorado), valendo-se das metodologias "learnig by doing" (aprender fazendo) e "peer learning" (aprendizagem entre pares). Nesse sentido, podese compreendê-lo como um espaço dinâmico de integração, promovendo e fortalecendo trocas de conhecimento entre todos os usuários. No caso dos fab labs, ele ainda viabiliza, por meio de seu ambiente (comunidade global + equipamentos), a possibilidade de cooperações internacionais de pesquisa em plataforma colaborativa, por meio do desenvolvimento de projetos em parceria com laboratórios de outros países.

A inserção de laboratórios de fabricação digital no contexto acadêmico é anterior ao início da vinculação brasileira à rede global Fab Lab Network, em 2011. Pode-se considerar como um dos pioneiros nesse contexto o LAPAC - Laboratório de automação e prototipagem para arquitetura e construção, vinculado à Faculdade de Engenharia Civil, Arquitetura e Urbanismo da UNICAMP. Liderado pela pesquisadora Profa. Gabriela Celani, o laboratório foi inaugurado em 2007 e até hoje possui um papel protagonista nesse campo de atuação, ainda que tenha optado por não se afiliar oficialmente à rede Fab Lab.

O surgimento do primeiro fab lab brasileiro se deu em 2011, a partir do cadastramento do laboratório de fabricação digital do grupo de pesquisa Digifab, da FAU/USP, liderado pelo Prof. Dr. Paulo Fonseca de Campos. Atualmente, são oito o número de fab labs de cunho acadêmico oficialmente vinculados à rede: cinco laboratórios dentro de Universidades e Institutos Federais e três laboratórios dentro de centros universitários particulares. Observa-se que a maior parte está vinculada a faculdades de engenharia e de arquitetura. Esse quadro é significativo da importância da relação entre tecnologia digital e materialização da forma para esses campos em especial.

Os fab labs possuem o diferencial de poder agregar múltiplos campos do conhecimento, criando interações entre os mais diversos cursos, que envolvam qualquer produto físico a ser criado, materializado e testado. Assim, mais do que constituir-se como um espaço multidisciplinar, o fab lab estimula a transdisciplinaridade em seu espaço. Ou seja, vivencia-se a colaboração e a fluidez de informação e criação entre as mais diversas disciplinas, confluindo com o espírito "Crowdthinking" como construção do pensamento transdisciplinar. Essa característica configura esse tipo de laboratório como um ambiente potencializador da inovação e de estímulo à aprendizagem horizontal, ao conhecimento partilhado e à colaboração coletiva. 


\section{Experiências construídas}

Uma das potencialidades observadas em tais experiências é a possibilidade de ampliar a concepção arquitetônica para além do ato de projetar. Para além de simulações computacionais de desenho paramétrico, os processos de fabricação digital vêm gerando também a possibilidade de trabalhar efetivamente a experiência construtiva e o trabalho em equipe. A partir da fabricação digital de suas partes, o processo construtivo pode ocorrer de forma integrada e participativa no âmbito da própria universidade.

A pesquisa propôs-se, em uma de suas duas vertentes, a documentar diversas experiências de concretização de pavilhões desenvolvidos por estudantes. Nesses exemplares, os alunos participam desde a concepção da forma até a montagem final do pavilhão. Nesse sentido, a produção de um pavilhão pelos alunos pode se tornar um instrumento de aprendizado privilegiado e altamente eficaz, pelo impacto da experiência integrada entre o criar (projetar), o concretizar (construir) e o vivenciar (apropriar-se dos espaços). Tais níveis de experimentação quase nunca estavam ao alcance das escolas de arquitetura. A fabricação digital parece vir possibilitar novamente a aproximação da experiência do processo construtivo na formação dos estudantes, bem como proporcionar a vivência espacial dos projetos concebidos.

A Architectural Association, de Londres, desenvolveu um programa educacional que foi pioneiro na associação entre pavilhões, fabricação digital e ensino de arquitetura. O estímulo inicial da ideia foi inspirado na proposta da Serpentine Gallery, segundo seus autores. Os Pavilhões de verão da $A A$, ou "Summer Pavilion programme" ocorreram entre os anos de 2005 e 2009, liderados pelos tutores Charles Walker e Martin Aluguer. Os alunos do segundo e terceiro anos produziram pavilhões de estudo com o objetivo de explorar o potencial arquitetônico da construção em madeira. Foi um programa bem sucedido que resultou na instalação de quatro pavilhões temporários (Fractal Pavilion, Bad Hair Pavilion, Swoosh Pavilion e Driftwood Pavilion), na Praça Bedford. Tais pavilhões atingiram um alto nível de realização, sendo publicados em diversas revistas e sites especializados. O programa recebeu patrocínio do fabricante de madeira Fineforest, que forneceu o material construtivo.

O Fractal Pavilion (2005/6) compunha-se de 2.000 peças de madeiras individuais, formadas por madeira estrutural composta (LVL). Ele consiste na colagem de folhas de madeira paralelas umas às outras. Baseado na proporção áurea, a composição da forma utiliza scripts que concebem uma família de componentes responsáveis por diminuir de tamanho para formar a estrutura, obtida a partir da geometria fractal. O Bad Hair Pavilion (2006/7), assim como o pavilhão anterior, deu-se a partir da colaboração de tutores, consultoria de engenheiros, técnicos e especialistas de materiais, aproximando o processo de aprendizagem a um efetivo escritório de arquitetura e de estruturas. Com características topológicas, sua estrutura apresenta um emaranhado de folhas de madeira coladas e parafusadas que se cruzam formando uma espécie de cúpula vazada.
Swoosh Pavilion (2007/8) foi o terceiro pavilhão construído no programa AA. A estrutura foi formada por 653 peças de laminas de madeira que foram moldadas a partir da prototipagem digital e uma máquina fresadora para o corte. A estrutura utiliza parafusos que facilitam o processo de montagem e desmontagem do pavilhão. A tintura branca aplicada na estrutura resultou em uma aparência fluida e leve. Inspirado nas formações de pedra escavada da cidade de Petra, Jordânia, Driftwood Pavilion (2008/9) foi o quarto e último pavilhão construído pelo programa. Ele foi composto por 28 placas de madeira com 4 milímetros de espessura cada uma. Foram gerados 112 desenhos técnicos a partir de programas computacionais a fim de fabricar e construir o pavilhão.

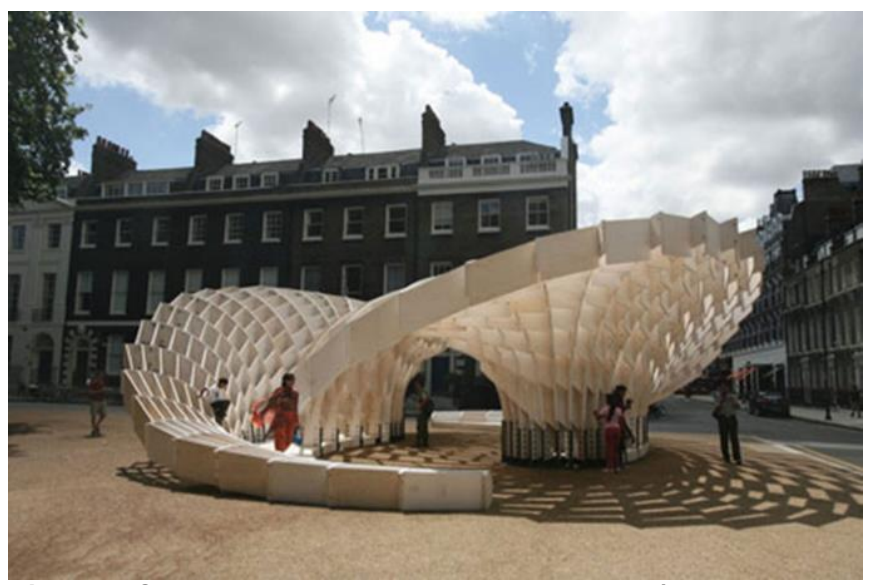

Figura 3: Swoosh Pavilion, terceiro pavilhão construído no programa AA. Fonte: http://designandmake.aaschool.ac.uk/aa-summerpavilions/

Todos os quatro pavilhões produzidos obedeceram a uma dinâmica de desenvolvimento didático semelhante. Primeiramente, eram oferecidos workshops envolvendo desenho paramétrico e algoritmos como ferramenta generativa, para equalizar o domínio dos softwares pelos alunos. O programa também contava com palestras teóricas, etapas de brainstorming de ideias conceituais e júri para seleção da proposta a ser efetivamente construída. A partir daí, passava-se às etapas de detalhamento, documentação, fabricação e montagem, com a produção de um documento de execução tecnicamente completo. Nesse âmbito, contavase com a consultoria de profissionais e escritórios reconhecidos, como o Arup. O programa dos "Pavilhões de verão", por meio de seu exemplo inaugural, estimulou muitas escolas a desenvolverem experiências semelhantes, sejam pontuais, objeto de um único workshop ou disciplina, ou um programa com continuidade anual, como foi o da própria AA.

Todavia, nem todos os pavilhões temporários desenvolvidos em faculdades de arquitetura possuem finalidade essencialmente didática. Outra vertente que vem adquirindo grande importância nos últimos anos é a produção de pavilhões com a finalidade de desenvolver pesquisas tecnologicamente avançadas. Nesses casos, são desenvolvidas estruturas fortemente inovadoras, que visam demonstrar os mais recentes desenvolvimentos em projeto assistido por computador e processos de produção 
digitalmente fabricados em arquitetura, especialmente os que envolvem processos robóticos personalizados. Nessa categoria, destaca-se a série de pavilhões desenvolvidos pelo Institute for Computational Design (ICD/ITKE) da Universidade de Stuttgart, Alemanha. Iniciado em 2010 e contando já com seis edições, esse programa anual de produção de um pavilhão de pesquisa surpreende a cada ano pelo grau de inovação alcançado, tanto em termos de pesquisa formal (baseada em biomimética) quanto pelo desafio tecnológico superado.

Como exemplo de desenvolvimento de processos distintos, o Research Pavilion de 2012 foi executado em fibra de vidro e polímero reforçados com fibra de carbono, tecidos na estrutura por braços robóticos. O pavilhão inaugurado em 2016, por sua vez, é o primeiro de seu tipo a empregar a costura industrial de elementos de madeira compensada em escala arquitetônica. A equipe de projeto foi composta por um conjunto de peritos que incluíam engenheiros e arquitetos, mas também biólogos, visto que a estrutura foi inspirada em ouriços. Essa excelência no desenvolvimento da robótica também fica evidenciada com sua escolha para sediar a conferência internacional "Fabricate 2017".

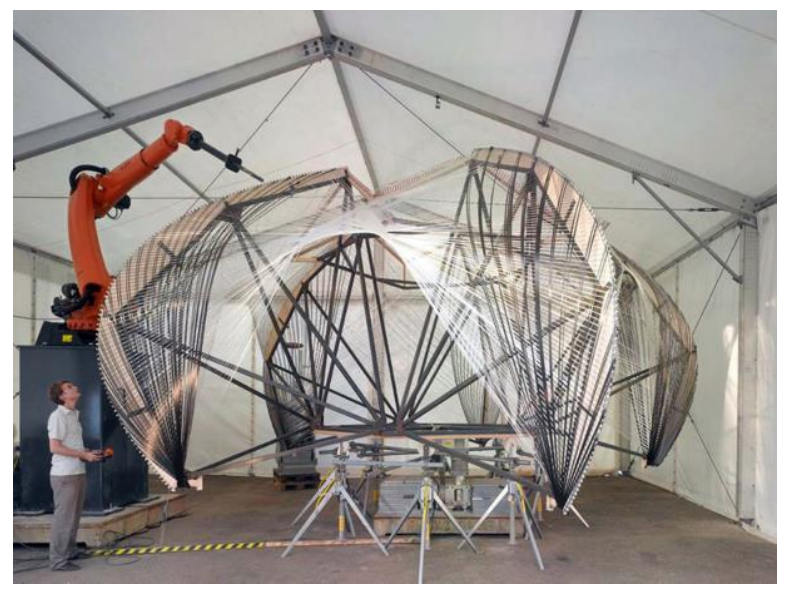

Figura 4: Produção do ICD/ITKE Research Pavilion de 2012. Fonte: http://icd.uni-stuttgart.de/?p=6553

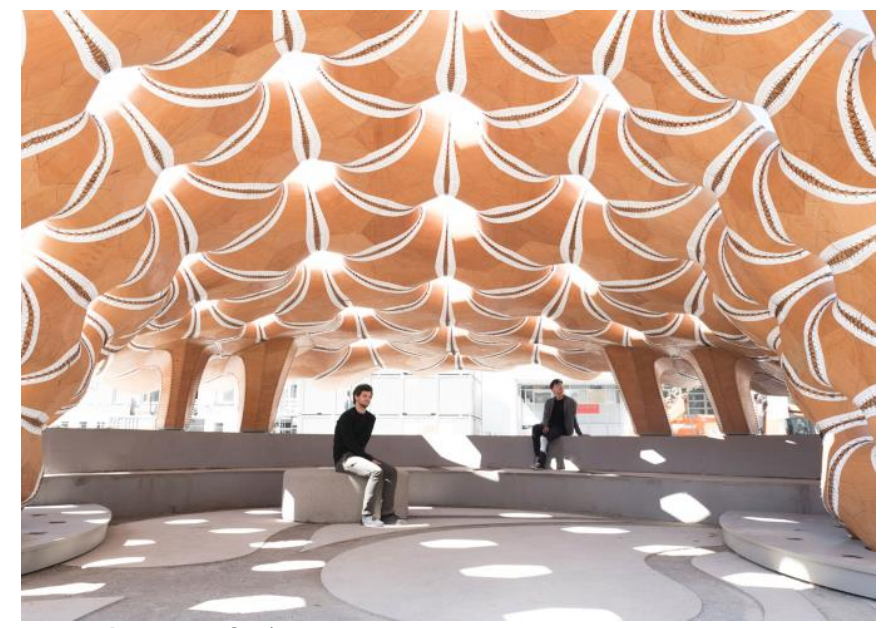

Figura 5: ICD/ITKE Research Pavilion de 2015-16. Fonte: http://icd.uni-stuttgart.de/?p=16220

No cenário brasileiro, todos os exemplares levantados associam-se à primeira categoria, de pavilhões acadêmicos de fins essencialmente didáticos. As experiências se assemelham ao processo desenvolvido pela AA em seus summer pavilions. É através da realização de workshops de desenho paramétrico, linguagem de programação e uso de algoritmos, que as habilidades iniciais dos estudantes são desenvolvidas. O software Rhinoceros aliado ao plugin Grasshopper é a ferramenta de modelagem 3D mais amplamente utilizada pelas diferentes universidades analisadas. Em um segundo momento, as técnicas de fabricação digital são introduzidas, especialmente o corte a laser, que é o processo mais utilizado. Os processos construtivos são constituídos da produção de partes digitalmente fabricadas e da montagem manual colaborativa. Não se identificou no Brasil o uso da robótica integrada à produção de pavilhões de pesquisa, seja para a elaboração de peças ou para a montagem final da estrutura.

Um exemplo do contexto brasileiro pode ser aportado pelo pavilhão denominado The Butterfly Gallery - Helicoidal Surfaces (2015), que foi resultado de um workshop desenvolvido pelo laboratório de fabricação digital LAMO 3D, apoiado pelo Programa de Pós-graduação em arquitetura (PROARQ) da FAU-UFRJ. Cerca de 50 pessoas participaram do projeto, entre professores, tutores e alunos. Esse workshop buscou explorar o tema "Estratégias Geométricas para a Fabricação Digital", instigando os alunos à reflexão teórica acerca do papel da geometria descritiva no contexto contemporâneo. Introduziu-se o uso de ferramentas de modelagem paramétrica e de fabricação digital, aliando o processo digital à construção. Após a fabricação de suas partes componentes, a estrutura foi montada à mão pelos alunos de forma colaborativa, com auxílio dos tutores. 


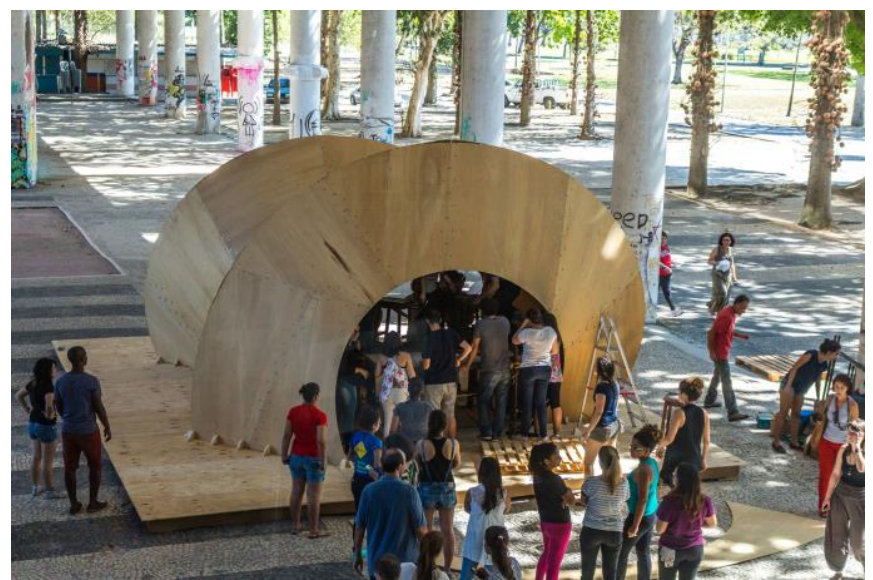

Figura 6: Pavilhão The Butterfly Gallery, 2015. Fonte: http://www.fau.ufrj.br/lamo3d/

Para além dos workshops extracurriculares, também se constatam tentativas de inserção da experiência de produção de pavilhões em disciplinas de graduação e pós-graduação. Nesse contexto, a disciplina eletiva de graduação "Prototipagem e Fabricação Digital", ministrada na FEC/UNICAMP pela Profa. Dra. Gabriela Celani, objetiva projetar e construir um pequeno pavilhão, utilizando modelagem paramétrica, prototipagem rápida e fabricação digital. Outra experiência pode ser destacada, promovida pelo Prof. Dr.Paulo Fonseca (Digifab/ Fab Lab SP). O Pavilhão Geometria Construtiva, desenvolvido no laboratório de fabricação digital (DFL) da Faculdade de arquitetura da Universidade do Porto, sob a orientação do Prof. Dr. José Pinto Duarte, em 2012, foi reproduzido recentemente no laboratório da FAU/USP. A estrutura de favo de mel com o interior coberto por painéis perfurados tem um total de 185 células hexagonais e 185 painéis. $O$ interesse da experiência está na demonstração das possibilidades advindas do compartilhamento de informações de projeto e de processos.

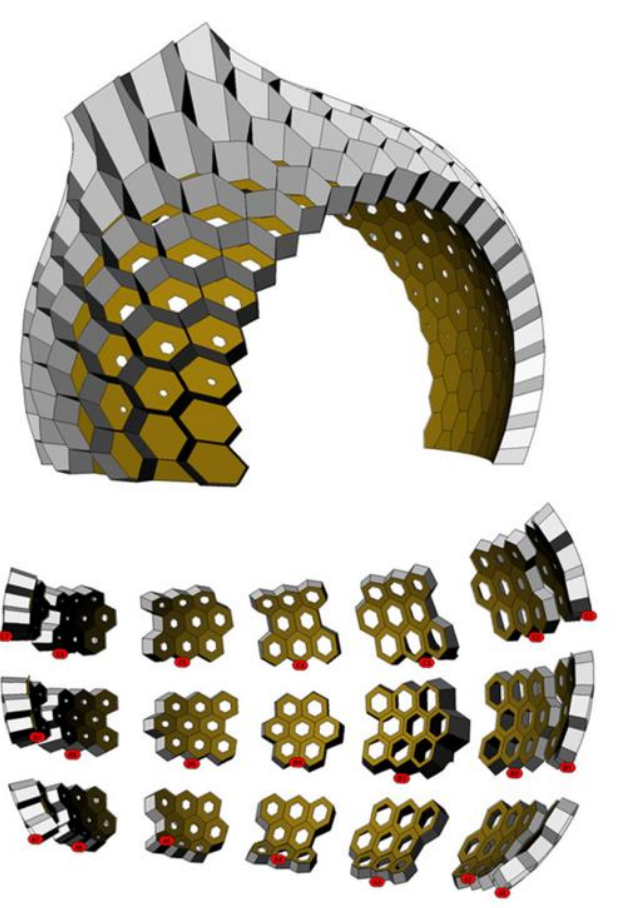

Figura 7: Esquema construtivo do Pavilhão Geometria construtiva, DFL, Faculdade de arquitetura da Universidade do Porto, 2011-12. Fonte: https://dfl.arq.up.pt/portfolio/constructive-geometry-pavilion$\underline{201112 /}$
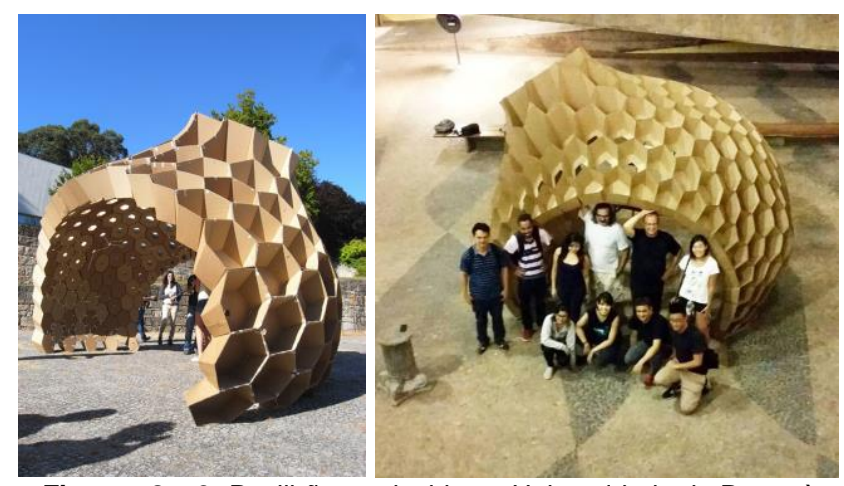

Figuras 8 e 9: Pavilhão produzido na Universidade do Porto, à esquerda, e na FAU/USP, à direita. Fontes:

https://dfl.arq.up.pt/portfolio/constructive-geometry-pavilion-201112/ e http://digifab.fau.usp.br/

\section{Considerações finais}

Apesar das limitações de acesso às tecnologias de ponta em fabricação digital, especialmente a robótica, constata-se já um grande avanço no quesito popularização dos laboratórios e na promoção de experiências pavilhonares em escala 1:1. Também se constatou a busca por integrar um aporte teórico significativo aos processos de projeto.

Visto que a manipulação de algoritmos para a produção de formas complexas em arquitetura é um processo relativamente novo no Brasil, é necessária a compreensão de que suas possibilidades vão além da produção da forma pela forma. É preciso a introdução de um novo processo 
projetivo e de uma metodologia conceitual que integre essas novas competências instrumentais à produção física dos componentes construtivos.

A pesquisa buscou evidenciar a importância da tipologia dos pavilhões temporários para a reflexão acerca dos novos paradigmas de concepção de formas arquitetônicas complexas, bem como das novas possibilidades proporcionadas pelo acesso às tecnologias de fabricação digital no contexto acadêmico. A criação do projeto, a princípio puramente abstrata, adquire um grau de impacto mais profundo na formação do estudante quando ele vivencia a experiência de prototipar, construir e finalmente experimentar concretamente o espaço concebido.

A reflexão empreendida na pesquisa buscou relacionar a influência de tais experiências à noção de campo ampliado da arquitetura. Procurou-se, também, destacar as potencialidades didáticas do estudo dessa tipologia nos cursos de arquitetura e urbanismo. Uma diversidade de questões pode ser explorada a partir de exercícios integradores, associando três níveis fundamentais da experiência arquitetônica: o projetar, o produzir e o vivenciar o espaço.

\section{Agradecimentos}

O presente artigo é fruto de uma pesquisa de iniciação científica PIBIC/ CNPq, vinculada à Universidade Federal de Alagoas, iniciada em agosto de 2015. Os autores agradecem às instituições citadas e aos demais pesquisadores envolvidos.

\section{Refêrencias}

Celani, G. (2014). Espaços para a interdisciplinaridade: laboratórios de fabricação digital na pesquisa, ensino eextensão. In: Arlindo Philippi Jr; Valdir Fernandes. (Org.). Práticas da interdisciplinaridade no ensino e pesquisa. 1ed.São Paulo: Manole, v. 1, p. 747-764.

Curtis, P (2008). Patio and Pavilion: The Place of Sculpture in Modern Architecture. Londres: Ridinghouse.

Eychenne, Fabien e Neves, Heloisa (2013). Fab Lab: A Vanguarda da Nova Revolução Industrial. São Paulo: Editorial Fab Lab Brasil.

Foster, H (2015). O complexo arte-arquitetura. São Paulo: Cosac Naify,

Gershenfeld, Neil. (2011).Fab: The Coming Revolution on Your Desktop-From Personal Computers to Personal Fabrication, Cambridge: Basic Books.

Jodidio, P (2011). Ten Years Serpentine Gallery Pavilions. Lisboa: Taschen.

Puente, M (2000). Pavilhões de exposição. Barcelona: Gustavo Gili

Self, M.; Walker, C. Making Pavilions. AA Agendas 9. Londres: Architectural Assossiation, 2009. Disponível em: https://issuu.com/aaschool/docs/making pavilions

Dempsey, A. , (2008). AA Agendas 8: Nine Problems in the Form of a Pavilion AA Agendas 9. Londres: Architectural Assossiation, Disponível em: https://issuu.com/aaschool/docs/nine problems

Stiny, G; Gips (1978), J. Algorithmic Aesthetics: Computer Models for Criticism and Design in the Arts. Berkeley: University of California Press,

Terzidis, K (2006). Algorithmic architecture. Harvard: Architectural Press,.

Vidler, A (2013). O campo ampliado arquitetura. In: SYKES, K. O campo ampliado arquitetura. São Paulo: Cosac Naify,

Sperling, d. M.; Herrera, P. C. (2015) - (Editores). Homo Faber: Digital Fabrication in Latin America São Carlos: Instituto de Arquitetura e Urbanismo, 2015. Disponível em: http://www.fec.unicamp.br/ celani/caadfutures 